\title{
Cross Protectivity of Yolk Immunoglobulin Anti-Hemagglutinin Protein of High Pathogenic Avian Influenza A subtypes H5N1 Administered on Chicken Infected by High Pathogenic Avian Influenza A subtypes H5N1
}

\author{
Suwarno*, Rahaju Ernawati, and Nanik Sianita Widjaja \\ Laboratory Virology and Immunology, Department of Microbiology, Faculty of Veterinary Medicine, Airlangga University, Indonesia \\ *Corresponding's Email: suwarno@fkh.unair.ac.id; (D) ORCiD: 0000-0002-8592-2877
}

\begin{abstract}
Yolk Immunoglobulin (IgY) against Avian Influenza (AI) is commonly used as immunotherapy and immunodiagnostic techniques. Application of $\operatorname{IgY}$ mixed in drinking water is known effective to inhibit AI replication. The effectivity of IgY anti-Hemagglutinin Protein (anti-HA) of High Pathogenic Avian Influenza (HPAI) clade 2.1 (A/Chicken/Blitar/2003) was tested against infection of High Pathogenic Avian Influenza clade 2.3.2 (A/Duck/Sidoarjo/2012). The inhibiting activity was observed through Immunohistochemistry. Sixty chickens were infected with $10^{5} \mathrm{EID}_{50} / \mathrm{ml}$ of HPAI clade 2.3.2 (A/Duck/Sidoarjo/2012). Yolk Immunoglobulin with different amounts $(0 \mu \mathrm{g}, 100 \mu \mathrm{g}, 200 \mu \mathrm{g}$ and $400 \mu \mathrm{g})$ were administered at three different times which were 24 hours before infection, at the time of infection, and 24 hours after infection. The observation was conducted for 7 days. During post infection observation, death chickens were managed for immunohistochemistry assay to observe the present of virion and IgY sialic acid 2,3-alfa galactosa (SA a 2,3 gal) blocking activity in septa alveoli. By the end of observation all chickens were euthanized for immunohistochemistry assay. The result showed that anti-HA IgY obtained from HPAI clade 2.1 could protecting infection of HPAI clade 2.3.2. According to immunohistochemistry assay, the administration of IgY can neutralize the infecting virus marked by the number of virions observed in septa alveoli of the lungs. Regarding the assay, the dose of $200 \mu \mathrm{g}$ and $400 \mu \mathrm{g}$ of IgY applied 24 hours before the infection, can reduce clinical signs and mortality of infected chicken $(80-100 \%)$. The best dose of the IgY to protect them from infection of clade 2.3.2 (A/Duck/Sidoarjo/2012) was $400 \mu \mathrm{g}$ administered 24 hours before infection. It could be concluded that administration of IgY anti-Haemaglutinin Protein (anti-HA) of High Pathogenic Avian Influenza (HPAI) clade 2.1 (A/Chicken/Blitar/2003) could protect chickens against the infection of HPAI clade 2.3.2 (A/Duck/Sidoarjo/2012), even though they belong different clades. The protection rate was $80-100 \%$. Further research should be done to discover the cross-protectivity of IgY as preventive method against HPAI outbreak.
\end{abstract}

Key words: Avian influenza virus, IgY anti-HA, Immunotherapy, Productivity.

\section{INTRODUCTION}

Avian Influenza (AI) is commonly known as fowl plaque which is a disease caused by infection of Influenza A virus which belongs to the family Orthomyxoviridae. This disease is susceptible for many species of birds (Bouma et al., 2009; Webby and Webster, 2003; De Jong et al., 1997). According to the genotype, It is classified into 16 Haemagglutinin and 9 Neuraminidase subtypes (Bergervoet et al., 2019). According to virulence, It is classified into two groups which are Low Pathogenic Avian Influenza (LPAI) and High Pathogenic Avian Influenza (HPAI) (OIE, 2016). Both LPAI and HPAI are originated from H5 and H7 subtypes (Bouma et al., 2009; Webby and Webster, 2003; De Jong et al., 1997), and it has become attention-getting to international trade community since HPAI causing a great loss by the outbreak, and the LPAI causing annual problem and has potency to mutate into HPAI (MacLachlan et al., 2016). It has become endemic in many countries such as Indonesia (Daniel et al., 2012).

Prevention has been already conducted such as routine vaccination and biosecurity management but annual outbreak remained ongoing. Poultry farm companies in Indonesia have conducting vaccination more than 400 million doses since 2004 (Bouma et al., 2009). AI is an enveloped segmented single-stranded negative sense RNA virus. Under electronic microscopes it is seen on pleomorphic, spherical, or velamentous forms. Its virion consists of 10-14.6 kb genome divided into eight segments arranged on helical-symmetrically order. It has seven structural proteins such as Haemagglutinin protein (HA), Neuraminidase protein (N), two Matrix proteins (M1 and M2), and three Polymerase proteins (PB1, PB2, and PA). HA and $\mathrm{N}$ are enveloped protein lining on the membrane form spikes that has important roles on pathogenicity, classification and neutralization of the virus (MacLachlan et al., 2016; Knipe and Howley, 2013). Specific antibody is usually used as a diagnostic rule or as a prevention for specific diseases. The antibody obtains from animals needs a good production procedure regarding to animal welfare instructions (Hau and Hendriksen, 2005). Antibody obtained from Yolk Immunoglobulin (IgY) is homolog to Immunoglobulin G (IgG) obtained from mammals. 
Recently the application of $\mathrm{IgY}$ obtained from eggs as immunotherapy is rising because the concentration of immunoglobulin is higher compared to IgG obtained from mammals. One of the privileges of obtaining immunoglobulin from chickens is that chickens have high sensitivity of antigen exposure, thus immune response and IgY production are persistent (Hau and Hendriksen, 2005).

AI virus transfers through the airway or orally, then Haemagglutinin protein of the virus bounds to the receptors of sialic acid alfa 2 and 3-galactosa (SA $\alpha 2,3$ gal) proteins. This binding triggers the fusion of the virus into cells (Knipe and Howley, 2013). This binding could be failed if specific antibody against HA protein block the process. HA antibody obtained from Yolk Immunoglobulin might have the potency to block this process to prevent AI infection in chickens. This research was conducted to know the effectivity of anti-HA from HPAI clade 2.1 (A/Chicken/Blitar/2003) against infection of HPAI clade 2.3.2 (A/Duck/Sidoarjo/2012).

\section{MATERIALS AND METHODS}

Sixty chickens (21 days-old) were used in this experiment. They were divided into three groups randomly. Each group consisted of four subgroups of treatments which were consisted of five chickens respectively. IgY was obtained by infecting HA protein of HPAI clade 2.1 (A/Chicken/Blitar/2003) into Specific Pathogen Free (SPF) layer chicken. IgY was extracted from the eggs, and stored at $-20^{\circ} \mathrm{C}$ (Narat, 2003). Yolk Immunoglobulin was given to each major group at three different times. IgY was administered 24 hours before infection, 24 hours after infection, and at the time of infection on Group I, II, and III respectively. The amounts of IgY given on each sub groups were $0 \mu \mathrm{g}, 100 \mu \mathrm{g}, 200 \mu \mathrm{g}$, and $400 \mu \mathrm{g}$ respectively. Each of dose was diluted on distilled water till the total volume was one ml. The research was conducted at Biosecurity Level-2 (BSL-2) of Faculty of Veterinary Medicine, Airlangga University Indonesia. The temperature was set at $16{ }^{\circ} \mathrm{C}$.

The chickens were infected with $10^{5} \mathrm{EID}_{50} / \mathrm{ml}$ dose of the antigen (A/Duck/Sidoarjo/2012). The observation has been started at the time of infection continuing for 7 days. During this period, all death chickens were recorded, then prepared for immunohistochemistry assay for determining the degree of cell destruction and sialic acid 2,3-alfa galactosa (SA $\alpha 2,3$ gal) blocking activity from anti-HA on cell tropism according to the antigen (virion detection) and antibody detection (anti-anti HA). By the end of observation, the rest of living chickens were euthanized through cervical dislocation method. Samples for immunohistochemistry were collected from the lung. The lung was dipped in $10 \%$ formalin buffer, then processed to make slides (Damayanti et al., 2004). Before the immunohistochemistry procedures applied to the slides, they were prepared for deparaffinization to wear the wax off. After cleaning up the slide, $250 \mu 1$ of primer antibody (anti H5N1 and anti-anti HA) that had been diluted (1:1600) was added to the slides, then it was incubated for 60 minutes. Then activity of peroxidase was blocked by adding three drops of hydrogen peroxidase $\left(\mathrm{H}_{2} \mathrm{O}_{2}\right)$, then it was incubated for 20 minutes. The slides were then rinsed using PBS for three times. Moreover, anti-rabbit conjugate labelled with Biotin-Streptavidin was added followed by DAB substrate. After that the slides were rinsed, they were dipped on Haematoxilyn for two minutes. They were transferred into Scott solution, then incubated for 2 minutes. They were rinsed, and then covered by cover glass. Positive result marked by the present of brown color on the slide (Damayanti et al., 2004). Obtained data was analyzed using ANOVA (Analysis of Variance) on Statistical Programs for Social Scientific (SPSS) program. The possible results were analyzed according to the Least Significance Different (LSD) analysis (Kusriningrum, 2012).

\section{Ethical approval}

The arrangement of this research had been approved by the ethics commission of experimental animals of Faculty of Veterinary Medicine Airlangga University, Indonesia.

\section{RESULTS AND DISCUSSION}

Observation has been conducted for seven days after the infection. It revealed that each treatment showed different effects according to mortality rate; the presence of virion captured on septa alveoli, and the presence of IgY in septa alveoli of chickens. In group I, chickens which were not treated by anti-HA were death on day 2 until day 3 after infection of (A/Duck/Sidoarjo/2012) (Diagram 1). In contrary, chickens treated with anti-HA (with amounts of 100 $\mu$ g, $200 \mu \mathrm{g}$, and $400 \mu \mathrm{g}$ ) showed healthy condition, and no clinical signs were present. Even though clinical signs were absence, one of the chickens administered with $100 \mu \mathrm{g}$ of antibody died on the second day after the infection while others remained intact until the end of the observation period (Diagram 1). It could be concluded that administration of anti-HA 24 hours before the infection could give $80-100 \%$ of protectivity (Table 1).

Group II which were treated with anti-HA at the same time of infection showed different results. Administration of anti-HA has protected the chickens from mortality only on day 1 after being infected. On the second day of infection, the 
mortality of chickens could be seen on each subgroup; primely on the subgroup not treated by anti-HA. The subgroup which were not treated with anti-AH $(0 \mu \mathrm{g})$ has started the mortality prior to the subgroup treated with $100 \mu \mathrm{g}$ of antiHA. Mortality still could be seen even on the subgroup treated by $400 \mu \mathrm{g}$ anti-HA (Diagram 2). According to the protection rate, administration of anti-HA at the same time of infection could gave 40-80\% of protection (Table 1).

While administration of anti-HA on Group III has completely protected the chickens from mortality only on day 1 after the infection, Mortality occurred on all subgroups even on the one administrated with $400 \mu \mathrm{g}$ of anti-HA. The mortality rate was significantly around $60 \%$ of the group population (Diagram 3). This rate is the largest among other treated groups. By the end of the observation, only subgroups of chickens treated with $200 \mu \mathrm{g}$ and $400 \mu \mathrm{g}$ of anti-HA have survived, while all chickens in other subgroups were death. It could be concluded that anti-HA given 24 hours after being infected gave a protection of $40 \%$ (Table 1). Regarding the dose of anti-HA, administrations of $200 \mu \mathrm{g}$ and $400 \mu \mathrm{g}$ of anti-HA are more protective than $100 \mu \mathrm{g}$ of anti-HA. They could give protection around 40-100\%. Administration of both doses 24 hours before the infection indicated a protection lasting longer than other times of administration (Diagrams 1-3). All data were collected, then processed into ANOVA analysis. According to the ANOVA analyses, the results showed a significant difference $(\mathrm{p}<0.05)$ (Table 2$)$. Thus, it was processed into LSD analysis. The results of analyses revealed that the administration of anti-HA is influenced by the time of administration and the doses. Administration of anti-HA 24 hours before infection could give aa appropriate protection more and last longer than the other administration times. This discovery was supported by the result of immune-histochemistry (IHC) assay. According to IHC results, there was an absence of AI virus in septa intra-alveola from chickens treated with $400 \mu \mathrm{g}$ antiHA on Group I. It was marked by the absence of dark-brown colour like formation observed on IHC slides (Figure 1). In contrast, the presences of AI virus observed on the chickens treated with anti-HA with $200 \mu \mathrm{g}$ and $100 \mu \mathrm{g}$ of anti-HA on Group I. The presence of AI virus also has been observed on the chickens which were not treated with anti-HA antibody (Figure 1). Administration of anti-HA in Group II and Group III seemed that they could not neutralize the virus as good as Group I, thus the number of virions have increased on both groups (Figure 1). The presents of virion inside the septaalveoli of lungs could disturb respiration of infected chickens (OIE, 2016). Regarding the effective dose of protection, $400 \mu \mathrm{g}$ of anti-HA gave best protection among others. In poultry, AI virus enters the host body through respiratory system and orally, then attaches to receptor sialic acid alfa 2,3-galactosa (SA $\alpha$ 2,3 gal) protein which laid on mucosal epithelium located on both respiratory and gastrointestinal tracts (Costahurtado et al., 2014; Webby and Webster, 2003). The transmission commonly occurs through contaminated water source, ingestion of contaminated feed and nasal discharge (Achenbach and Bowen, 2011).

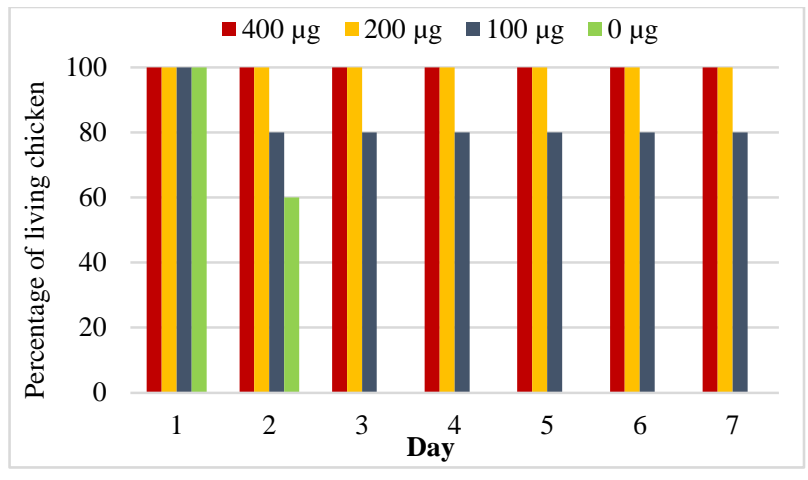

Diagram 1. Percentage of living chicken after administration of anti-HA 24 hours before infection

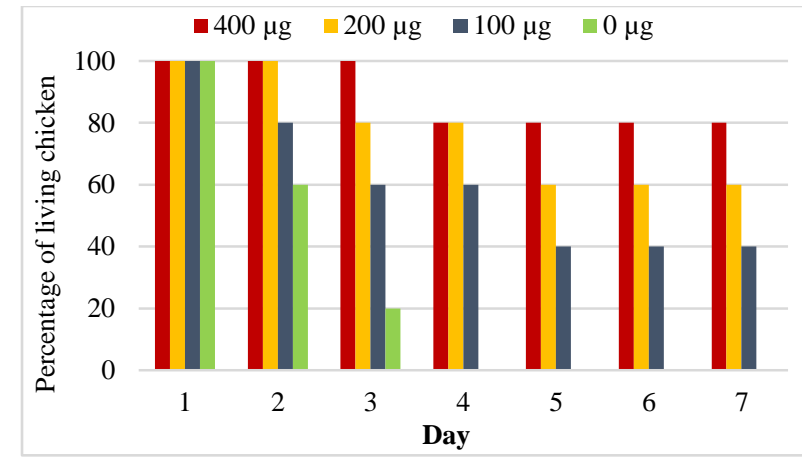

Diagram 2. Percentage of living chicken after administration of anti-HA at infection time

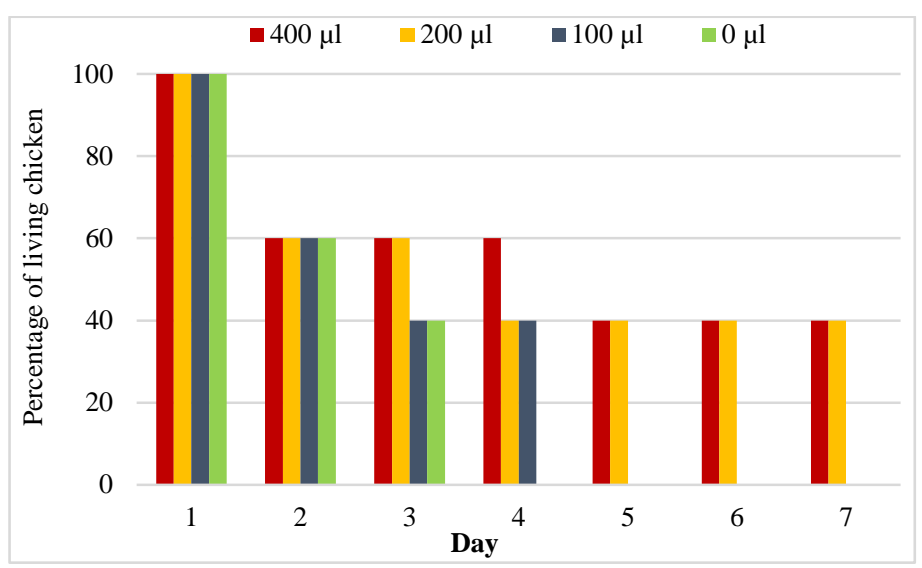

Diagram 3. Percentage of living chicken after administration of anti-HA 24 hours after infection 
Table 1. Protectivity rate of anti-HA antibody obtained from egg yolk (IgY).

\begin{tabular}{lccc}
\hline \multicolumn{4}{c}{ Application of Antibody Anti-HA (IgY) } \\
\hline Dose & 24 hours before infection (\%) & 0 hours before infection (\%) & 24 hours after infection (\%) \\
\hline $0 \mu \mathrm{g} / \mathrm{head}$ & 0 & 0 & 0 \\
$100 \mu \mathrm{g} / \mathrm{head}$ & 80 & 40 & 0 \\
$200 \mu \mathrm{g} / \mathrm{head}$ & 100 & 60 & 40 \\
$400 \mu \mathrm{g} / \mathrm{head}$ & 100 & 80 & 40 \\
\hline
\end{tabular}

$\%$ : means protectivity rate

Table 2. The amount of IgY and the time administration influence the protectivity of chickens

\begin{tabular}{|c|c|c|}
\hline Amount & Time of apllicatipn of anti-HA & $($ Mean \pm SD $)$ \\
\hline \multirow{3}{*}{400} & D-1 & $4,8^{\mathrm{a}} \pm 0,83$ \\
\hline & D-0 & $10^{\mathrm{b}} \pm 1,41$ \\
\hline & $\mathrm{D}+1$ & $23,2^{\mathrm{c}} \pm 1,09$ \\
\hline \multirow{3}{*}{200} & D-1 & $12,8^{\mathrm{d}} \pm 1,09$ \\
\hline & $\mathrm{D}-0$ & $18,8^{\mathrm{e}} \pm 1,09$ \\
\hline & $\mathrm{D}+1$ & $35,2^{\mathrm{f}} \pm 1,09$ \\
\hline \multirow{3}{*}{100} & D-1 & $30,8^{\mathrm{g}} \pm 1,09$ \\
\hline & $\mathrm{D}-0$ & $35,6^{\mathrm{f}} \pm 0,89$ \\
\hline & $\mathrm{D}+1$ & $41,2^{\mathrm{h}} \pm 1,09$ \\
\hline \multirow{3}{*}{0} & D-1 & $47,6^{i} \pm 0,89$ \\
\hline & $\mathrm{D}-0$ & $47,2^{\mathrm{i}} \pm 1,09$ \\
\hline & $\mathrm{D}+1$ & $47,6^{\mathrm{i}} \pm 0,89$ \\
\hline
\end{tabular}

Different superscript on the same column showing significant different (p<0.05). D-1: 24 h before infection, D-0: at the time of infection, D+1: 24 hours after infection.

In this research anti-HA obtained from egg yolk called IgY was used which is equivalent to mammalian Immunoglobulin $\mathrm{G}(\mathrm{IgG})$, since it is distinguished as the ancestor. As the $\operatorname{IgY}$ is equivalent to mammalian $\mathrm{IgG}$, it has similar functions as the main humoral immune-system to eradicate antigens (Agrawal et al., 2016). IgY is frequently used as substitution from mammalian antibody because the production process is more respecting animal welfare. Moreover, it is easier to be done and the amount of immunoglobulin obtained is larger among small-sized animals (Narat, 2003; Ko and Ahn, 2007; Wen et al., 2012; Agrawal et al., 2016). Its capability to binding and target specifity is higher than mammalian Immunoglobulin $\mathrm{G}(\mathrm{IgG})$ which makes it has potential as therapeutic therapy for respiratory infections (Abbas et.al., 2018). Application of IgY is noticed capable to prevent bacterial and viral infections (Narat, 2003; Ko and Ahn, 2007; Wen et al., 2012; Agrawal et al., 2016). It could be applied in human too which gives many advantages (Pereira et.al., 2019; Constantin et. al., 2020). According to the IHC of anti-HA detection, anti-HA administered orally could be seen on septa alveoli of lungs as brown color (Figure 2). Immunotherapy given orally is capable to block receptors on the epithelium of mucosa on digestion system. It is directly transported through all over the body absorbed by intestine to capillaries, then transported to portal vein in liver and then vena cava in heart (Rahimi et al., 2007). Administration of anti-HA 24 hours before being infected suggested that it could compete binding of the virus to receptor SA $\alpha 2,3$ gal protein. Administration of anti-HA obtained from horses given to the mouse intraperitoneal before infection can give $100 \%$ protection (Lu et al., 2006).

This research used anti-AH obtained HPAI clade 2.1 (A/Chicken/Blitar/2003) against the infection of HPAI clade 2.3.2 (A/Duck/Sidoarjo/2012). Both viruses belong to different clades, different hosts and different time isolations. According to the results, even both viruses are different; the cross-protection was observed. This finding extents the fact that cross-reactivity among clades of H5 subtypes occurred (Dharmayanti et al., 2017; Ducatez et al., 2011). This evidence is not only occurred among H5 subtypes. Cross-reactivity also occurred among H7 subtypes to H3 and H4 subtypes. It is noticed that cross-reactivity between H7 and H3 is stronger than H7 and H4 (Guo et al., 2016). Crossreactivity among subspecies in same family not only occurs in AI. It also occurs in Newcastle Disease (Aldous et al., 2016). The distinct point is that cross-reactivity in Newcastle Disease seems stronger than AI. Both viruses are single stranded negative sense RNA virus. RNA viruses are easy to mutate because their polymerase enzymes lack of proofreading. Among them, the mutation rate of AI is higher because its genome arranged on some segments leading to antigenic shift and antigenic drift (MacLachlan et al., 2016).

This finding reveals the possibility of anti-HA hyper-immune serum application on AI prevention. Routine vaccination as one of the main prevention methods could be possibly optimized by application of anti-HA serum orally. Further researches need to be done since this research is conducted in controllable and variables environment. 
A
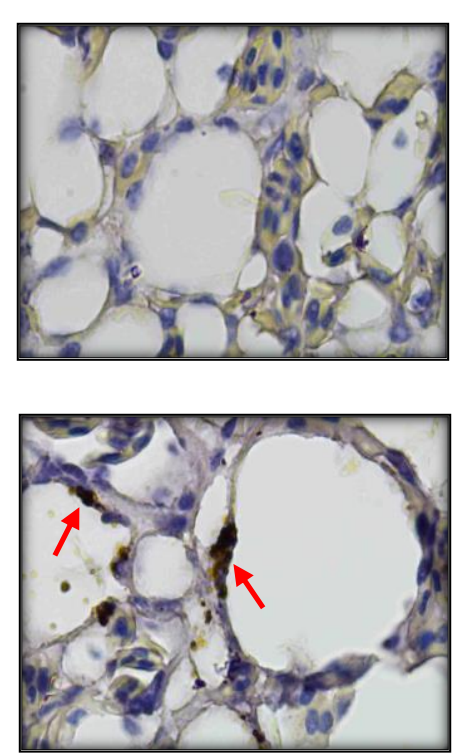

C
B
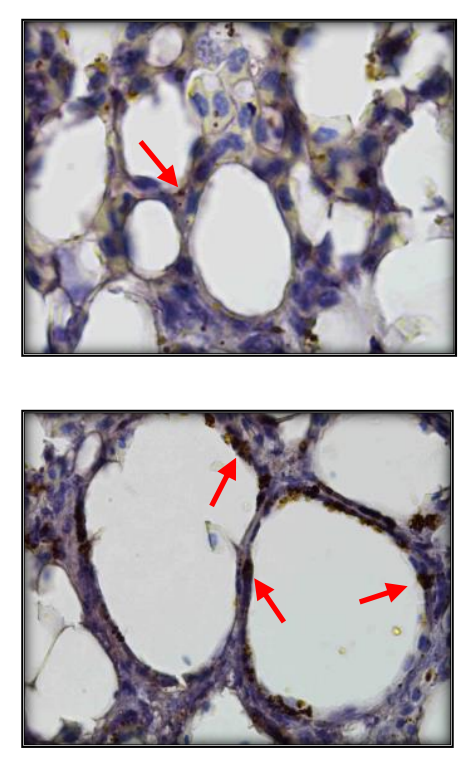

D
A
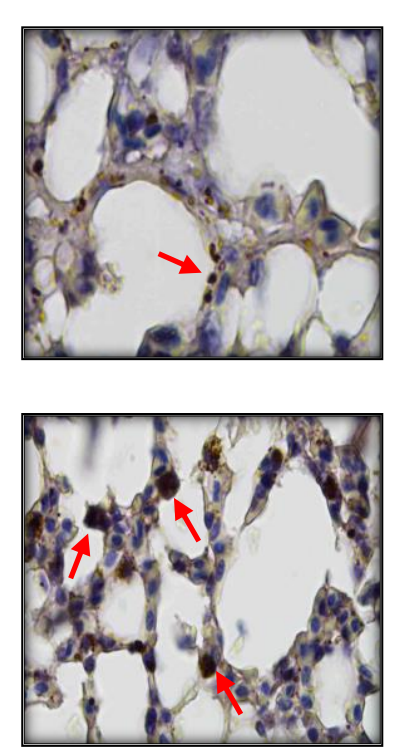

C
B
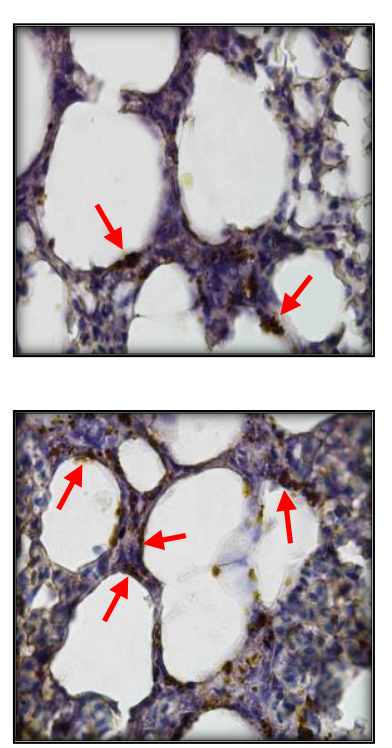

II
A
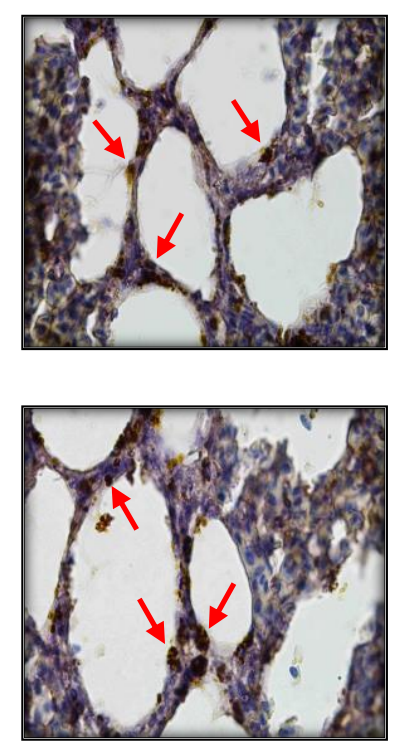

C
B
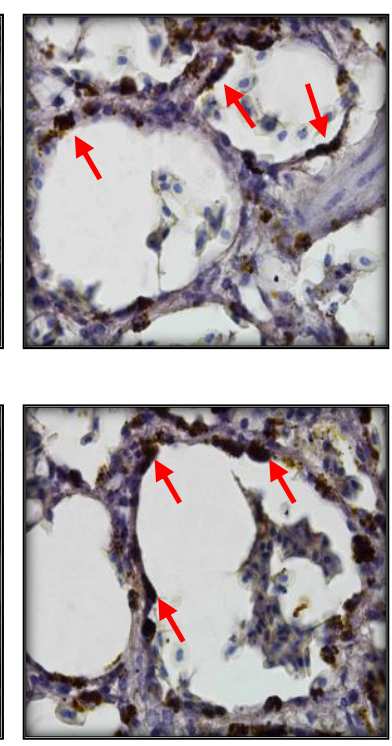

D

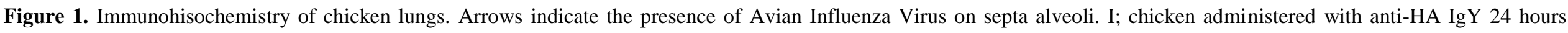

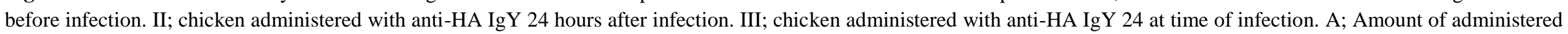
$\mathrm{IgY}$ is $400 \mu \mathrm{g}$. B; Amount of administered IgY is $200 \mu \mathrm{g}$. C; Amount of administered IgY is $100 \mu \mathrm{g}$. D; Amount of administered Ig Y is $0 \mu \mathrm{g}$. 
A
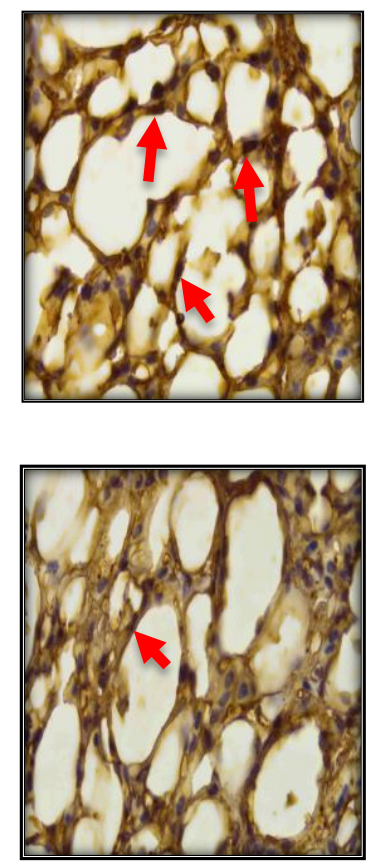

C
B
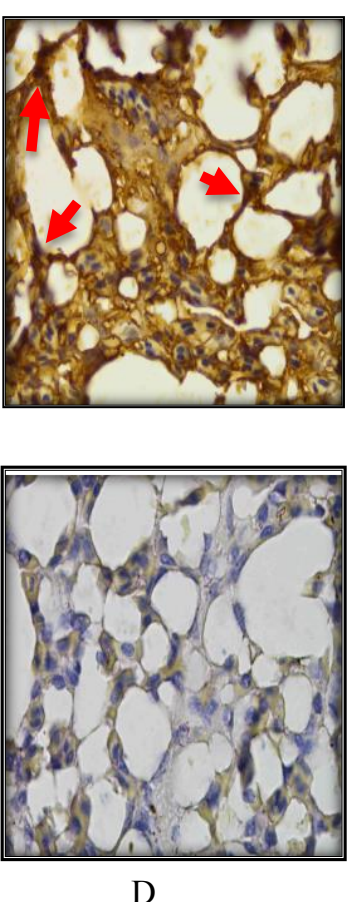

I
A
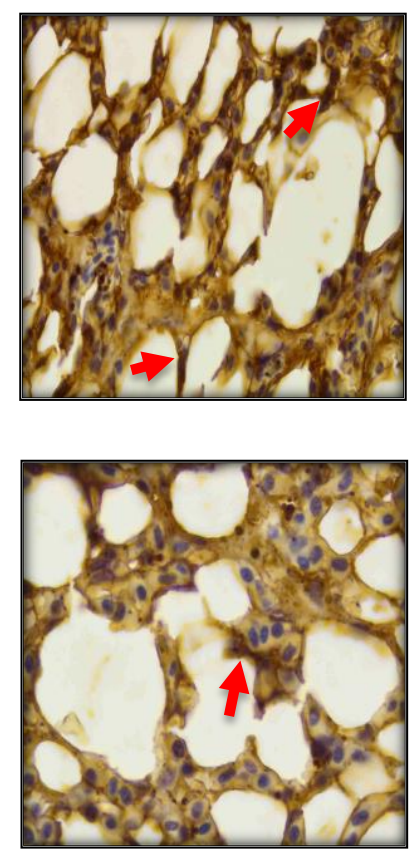

C
B
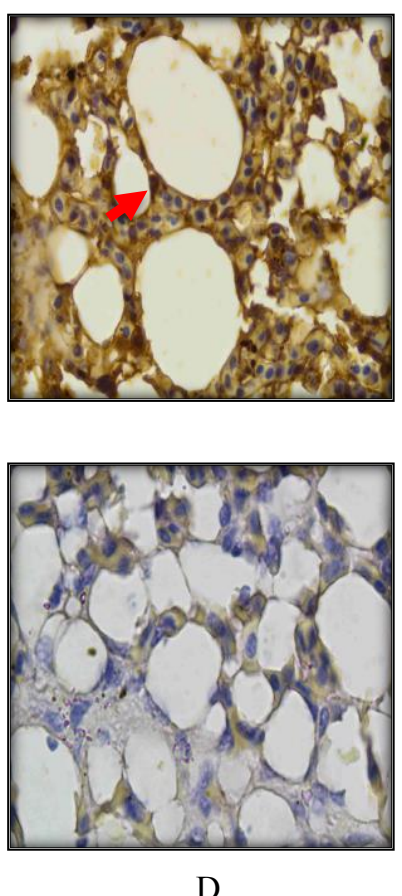

II
A
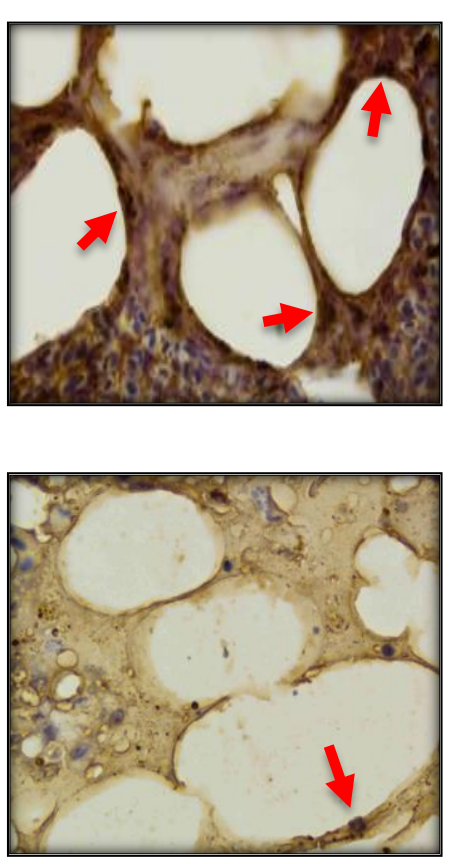

C
B
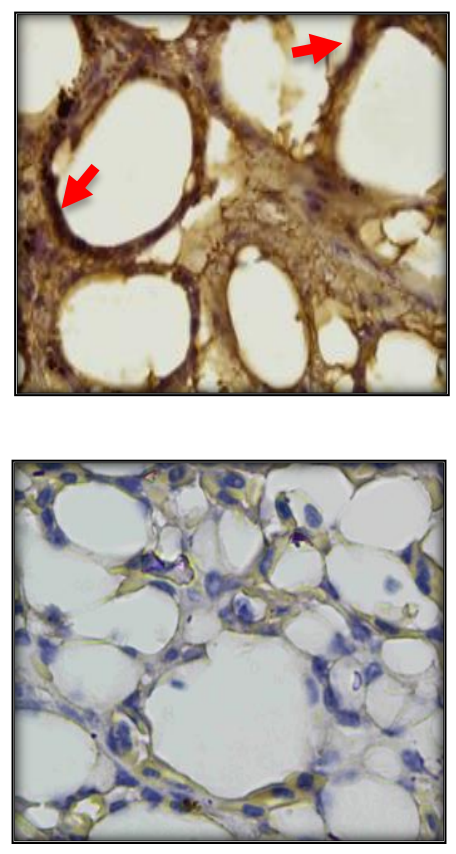

D

III

Figure 2. Immunohisochemistry of chicken lungs. Arrows indicate the blocking activity of anti-HA IgY on Avian Influenza Virus on septa alveoli. I; chicken administered with antiHA IgY 24 hours before infection. II; chicken administered with anti-HA IgY 24 hours after infection. III; chicken administered with anti-HA IgY 24 at time of infection. A; Amount of administered IgY is $400 \mu \mathrm{g}$. B; Amount of administered $\operatorname{IgY}$ is $0 \mu \mathrm{g}$. 
It can be concluded that application of anti-HA obtained High Pathogenic Avian Influenza (HPAI) clade 2.1 (A/Chicken/Blitar/2003) could give a protection from infection of HPAI clade 2.3.2 (A/Duck/Sidoarjo/2012), although they were originated from different clades. The protection rate was 80-100\% applied 24 hours before infection.

\section{DECLARATIONS}

\section{Authors' contribution}

Suwarno contributed on data analysis and the write up of the manuscript. I also contribute on the production of IgY and formulating the dose of administered IgY and processing the sample on Immunohistochemistry assay. Rahaju Ernawati and Nanik Sianita Widjaya contributed on data analysis and the write up of the manuscript and calculating the dose of $\mathrm{EID}_{50} / \mathrm{ml}$ and conducting the challenge test. All authors read and approved the final draft of manuscript.

\section{Competing interests}

The authors have not declared any conflict of interests.

\section{Consent of publish}

All the authors agree to publish this manuscript in World`s Veterinary Journal.

\section{Acknowledgements}

This research was fund by Director of Research and Community Development Ministry of Technology and Higher Education on 2016.

\section{REFERENCES}

World Organization for Animal Health (OIE) (2016). Avian influenza (infection with avian influenza viruses). Manual of Diagnostic Tests and Vaccines for Terrestrial Animals, pp. 1-23. Available at: https://www.oie.int/fileadmin/Home/eng/Health_standards/tahm/3.03.04_AI.pdf

Achenbach JE and Bowen RA (2011).Transmission of avian influenza a viruses among species in an artificial barnyard. PLoS ONE, 6(3):1-7. DOI: https://doi.org/10.1371/journal.pone.0017643

Agrawal R Hirpurkar SD Sannat C and Gupta AK (2016). Comparative study on immunoglobulin Y transfer from breeding hens to egg yolk and progeny chicks in different breeds of poultry. Veterinary World, 9(4): 425-431. DOI: https://dx.doi.org/10.14202\%2Fvetworld.2016.425-431

Aldous EW and Alexander DJ (2016). Detection and differentiation of newcastle disease virus ( avian paramyxovirus type 1 ).Avian Pathology,30:117128/ DOI: https://doi.org/10.1080/03079450120044515

Bergervoet SA, Pritz-Verschuren SBE, Gonzales JL, Bossers A, Poen MJ, Dutta J, Khan Z, Kriti D, Van Bakel H, Bouwstra R et al. (2019).Circulation of low pathogenic avian influenza (LPAI) viruses in wild birds and poultry in the Netherlands 2006-2016. Scientific Reports, 9(1):1-12. DOI: https://doi.org/10.1038/s41598-019-50170-8

Bouma A Claassen I Natih K Klinkenberg D Donnelly CA Koch G and Boven MV (2009). Estimation of transmission parameters of H5N1 avian influenza virus in chickens. PLoS Pathogens, 5(1):1-13. DOI: https://doi.org/10.1371/journal.ppat.1000281

Costa-hurtado M, Afonso CL, Miller PJ, Spackman E, Kapczynski DR, Swayne DE, Shepherd E, Smith D, Zsak A and Pantin-Jackwood M (2014). Virus interference between H7N2 low pathogenic avian influenza virus and lentogenic newcastle disease virus in experimental co-infections in chickens and turkeys. Veterinary Research, 45(1): 1-11. DOI: https://dx.doi.org/10.1186\%2F1297-9716-45-1

Wright PF Neumann G and Kawaoka Y (2013). Orthomyxoviruses. In Knipe DM and Howley PM (Editor in Chief), Fields Virology $6^{\text {th }}$ Edition, Philadelphia, PA 19103, pp. 1186-1243.

Guo L, Wang D, Zhou H, Wu C, Gao X, Xiao Y, Ren L, Paranhos-Baccalà G, ShuY, Jin Q and Wang J (2016). Cross-reactivity between avian influenza A (H7N9) virus and divergent H7 subtypic- and heterosubtypic influenza A viruses. Scientific Reports, 6: 1-8. DOI: https://dx.doi.org/10.1038\%2Fsrep22045

Hau $\mathrm{J}$ and Hendriksen CFM (2005). Refinement of polyclonal antibody production by combining oral immunization of chickens with harvest of antibodies from the egg yolk. ILAR Journal, 46(3): 294-299. DOI: https://dx.doi.org/10.1093/ilar.46.3.294.

Indriani R, Dharmayanti NLPI and Martindah E (2017). Cross - reaction of duck and chicken sera against avian influenza H5N1 virus clades 2.1.3 and 2.3.2 antigens by hemagglutination inhibition test. Jurnal Biologi Indonesia, 13(2): 325-329. DOI: https://dx.doi.org/10.14203/jbi.v13i2.3407

de Jong JC, Claas ECJ, Osterhaus ADME, Webster RG and Lim WL (1997). A pandemic warning?.Nature, 389: 554-555. DOI: https://dx.doi.org/10.1038\%2F39218

Ko KY and Ahn DU (2007).Preparation of immunoglobulin Y from egg yolk using ammonium sulfate precipitation and ion exchange chromatography. Poultry Science, 86(2): 400-407. DOI: https://doi.org/10.1093/ps/86.2.400

Lu J, Guo Z, Pan X, Wanf G, Zhang D, Li Y, Tan B, Ouyang L and Yu X (2006). Passive immunotherapy for influenza A H5N1 virus infection with equine hyperimmune globulin F(ab'1)2 in mice. Respiratory Research, 7: 1-7. DOI: https://doi.org/10.1186/1465-9921-7-43

Narat M (2003). Production of Antibodies in Chickens.Food Technology and Biotechnology, 41(3): 259-267.

Rahimi S, Zahra MS, Salehi TZ, Torshizi MAK and Grimes JL (2007). Prevention of Salmonella infection in poultry by specific egg-derived antibody. International Journal of Poultry Science, 6(4): 230-235. DOI: http://dx.doi.org/10.3923/ijps.2007.230.235

Webby RJ and Webster RG (2003). Are we ready for pandemic influenza?. Science, 302(5650): 1519-1522. DOI: https://doi.org/10.1126/science. 1090350

Wen J, Zhao S, He D, Yang Y, Li Y and Zhu S (2012). Preparation and characterization of egg yolk immunoglobulin Y specific to influenza B virus. Antiviral Research, 93(1): 154-159. DOI: https://doi.org/10.1016/j.antiviral.2011.11.005

Abbas AT, El-Kafrawy SA, Sohrab SS and Azhar EIA (2019). IgY antibodies for the immunoprophylaxis and therapy of respiratory infections. Human Vaccines and Immunotherapeutics, 15(1): 264-275. DOI: https://doi.org/10.1080/21645515.2018.1514224

Constantin C, Neagu M, Supeanu TD, Chiurciu V and Spandidos DA (2020). IgY-turning the psge toward passive immunization in COVID-19 infection (Review). EXPERIMENTAL AND THERAPEUTIC MEDICINE, 20:151-158. DOI: https://doi.org/10.3892/etm.2020.8704

Pereira EPV, van Tillburg MF, Florean EOPT and Guedes MIF (2019). Egg yolk antibodies (IgY) and their applications in human and veterinary health:review. International Immunopharmacology, 73: 293-303. DOI: https://doi.org/10.1016/j.intimp.2019.05.015 